\title{
Water and sodium imbalance in COPD patients
}

\author{
G. Valli, A. Fedeli, R. Antonucci, P. Paoletti, P. Palange
}

ABSTRACT: Water and sodium imbalance in COPD patients. G. Valli, A. Fedeli, R. Antonucci, P. Paoletti, P. Palange.

Water retention and hyponatraemia are typically observed in the final stages of Chronic Obstructive Pulmonary Disease (COPD) and the onset of edema is a poor prognostic factor. For several years the pathogenesis of edema in COPD patients was attributed to heart impairment because of pulmonary hypertension, but the evidence that cardiac output is often adequate for the metabolic demands has suggested, since 1960 , that the pathogenesis of edema in these patients would be correlated with gas exchange impairment and in particular with car- bon dioxide $\left(\mathrm{CO}_{2}\right)$ retention. The gas exchange impairment induces, in these patients several hormonal abnormalities: renin (Rn), angiotensin II (AnII), aldosterone (Ald), atrial natriuretic peptide (ANP), vasopressin (ADH) and endothelial factors are some of the factors involved. The systemic response to hypercapnia has the effect of reducing the renal blood flow and, as a result, increasing water and sodium retention with the final effect of edema and hyponatraemia. The aim of this brief review is to highlight the current knowledge on renal/hormonal abnormalities in COPD and their therapeutic implications. Monaldi Arch Chest Dis 2004; 61: 2, 112-116.

Keywords: Cor Pulmonale, Hypercapnia, Edema, COPD, renal vascular resistance.

Servizio di Fisiopatologia Respiratoria; Dipartimento di Medicina Clinica, University of Rome "La Sapienza” V.le dell'Università 37, 00185 Rome - Italy.

Correspondence: Paolo Palange, MD; Dipartimento di Medicina Clinica; V.le Università, 37; 00185 Rome - Italy; e-mail paolo.palange@uniroma1.it

Water retention and hyponatraemia are typically observed in the final stages of chronic obstructive pulmonary disease (COPD). In 1960, Campbell and Short [1] pointed out that, in patients with COPD, edema is almost invariably associated with gas exchange impairment and in particular with carbon dioxide $\left(\mathrm{CO}_{2}\right)$ retention. Since then solutewater retention in COPD has been considered to be the result of electrochemical imbalance (enhanced renal/tubular $\mathrm{H}^{+} / \mathrm{Na}^{+}$exchange) and/or renal hemodynamic abnormalities [2]. Many patients with COPD are also unable to normally excrete a water load, and this defect that can be confirmed in the absence of overt edema, is associated with a decrease in sodium excretion and has been reported to be proportional to the severity of $\mathrm{CO}_{2}$ retention [3]. In hypoxemic normocapnic patients with pulmonary fibrosis or lung emphysema water retention and peripheral edema are very uncommon and when they occur a transient increase in $\mathrm{CO}_{2}$ during an exacerbation or during sleep should be ruled out.

In advanced COPD edema has been reported in a large proportion of patients but its exact incidence is not known. The onset of edema is a poor prognostic factor. Renzetti and co-workers [4] reported a four-year mortality rate of $73 \%$ in patients with "cor pulmonale", compared with $53 \%$ for the whole COPD group. More recently, Hodgking has shown a $60 \%$ of mortality up on five years in edematous COPD patients [5].

It must be clearly stated that edema formation in COPD patients is not cardiac in origin. In most patients, even when they are frankly edematous, cardiac output is adequate for the metabolic demands, unless there is a significant co-existent cardiac disease $[6,7]$.

Figure 1 summarises the principal events that are supposed to induce edema in COPD patients. The aim of this brief review is to highlight the current knowledge on renal/hormonal abnormalities in COPD and their therapeutic implications.

\section{The role of hypercapnia}

During acute edematous exacerbations of COPD renal blood flow is reduced $[8,9]$, but increases when the clinical status improves [9]. However, in edematous COPD patients the glomerular filtration rate (GFR) is normal or only slightly reduced $[8,10]$ and thus the serum creatinine level remain normal until the end stage of the disease. In patients with moderate hypoxemia, mild hypercapnia, normal cardiac output, and no evidence of intrinsic renal disease, the significant reduction in effective renal blood flow (ERPF), associated with normal GFR, increases the filtration fraction $(\mathrm{FF})$ and consequently induces $\mathrm{Na}^{+}$retention. Recently in a group of COPD patients, Sharkey and co-workers measured, non invasively by Doppler ultrasonography, the pulsatility index (an index of renovascular resistances), showing in these patients a lack in renal vasodilatation following a protein meal (an effect known as renal functional reserve) and even an increase in vasocon- 


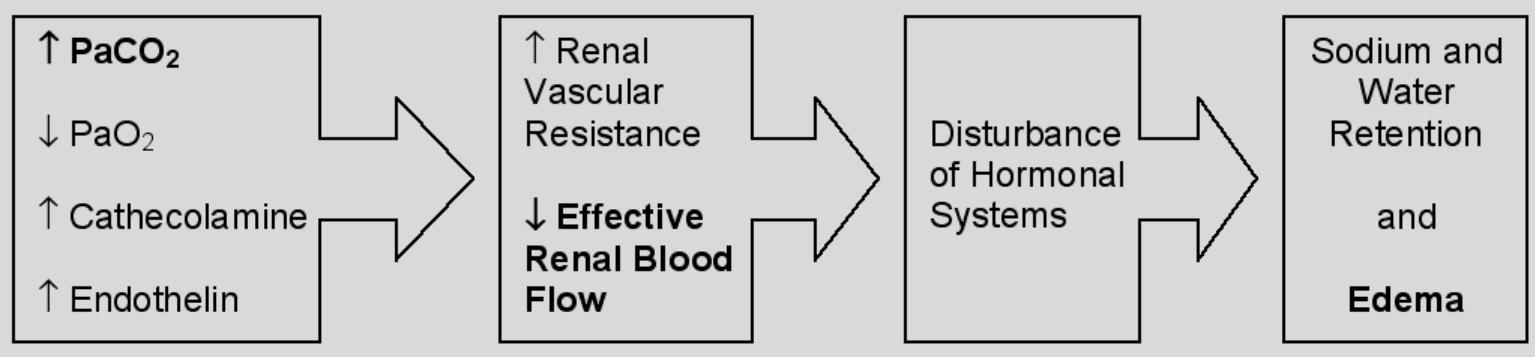

Fig. 1. - Pathogenesis of peripheral edema in COPD patients.

striction in more hypercapnic patients [11]. These findings indicate that arteriolar renal resistances are increased, perhaps because of local adrenergic discharge secondary to hypercapnia.

In the initial phase of COPD, renal perfusion is usually normal but when $\mathrm{CO}_{2}$ retention develops, renal blood flow decreases [12-13].

Hypercapnia reduces renal blood flow by means of a direct renal vasoconstriction [14]. Moreover, hypercapnia induces an increment of noradrenalin levels, that causes a reduction in renal blood flow, through peripheral vasodilatation that inactivates baro-receptors and direct central sympathetic stimulation [15].

\section{Role of hypoxemia}

Hypoxemia alone does not seem to induce significant changes in renal hemodynamics and/or $\mathrm{Na}^{+}$and water homeostasis, although oxygen administration has been shown to exert a vasodilator effect in hypoxemic normocapnic COPD patients [16]. Sharkey and co-workers [17] had recently documented that in hypoxemic COPD patients the raise in oxygen saturation from $98 \%$ to $99 \%$ reduces the renovascular resistance and, consequently, increases renal blood flow. This decrease in renovascular resistance was reversed by the addition of inhaled carbon dioxide, despite maintaining hyperoxemia. In hypercapnic patients neither short term oxygen therapy or infusion of low dose dopamine improve renal hemodynamics [18]. This suggests that the increase in $\mathrm{CO}_{2}$ levels mainly drives the renal haemodynamic response to changes in arterial blood gases. The vast majority of studies in COPD patients showed a decrease in RBF in the presence of hypoxemia $[14,16,18]$ but the mechanism whereby hypoxemia affects RBF is not fully understood. However, clinical experience suggests that correction of hypoxemia by long term oxygen therapy in hypercapnic hypoxemic COPD patients may result in significant natriuresis and improves renal function [19]. Finally, the finding that hypoxemic COPD patients are unresponsive to L-arginine, while it induces vasodilatation in normal subjects, suggests that a disturbance on NO pathway may play an important role on COPD renovascular response to hypoxia [20].

Honig and co-workers [21], in an animal study, found that changes in renal blood flow secondary to hypoxemia are abolished by denervation of peripheral chemoreceptors and are reduced by renal denervation, while adrenalectomy does not induce changes. These findings suggest a relevant role of peripheral nervous system. In a study on a group of renal transplant subjects, kidney denervation does not totally abolish renal response to hypoxemia [22].

\section{Role of the PRA-PA system}

Disturbance of the hormonal system are common in COPD patients, especially during acute exacerbation of respiratory failure. Hypoxemia and hypercapnia induce systemic alterations that involve various organs like kidney, adrenal cortex, heart and brain with increased secretion of renin (Rn), angiotensin II (AnII), aldosterone (Ald), atrial natriuretic peptide (ANP) and vasopressin (ADH).

As a consequence of reduced renal blood flow, and as in most edematous diseases whit reduction of renal blood flow without reduction of GRF, COPD patients present a state of secondary hyperaldosteronism [8, 23, 24]. The activation of PRAPA system occurs late in the course of the disease and concurs to worsen the ability to excrete $\mathrm{Na}^{+}$ and water. Patients with COPD may have levels of Rn, AnII and Ald 2-3 times higher than normal subjects, but usually lower than those observed in patients with congestive heart failure [25]. In animal studies acute hypoxia has been reported to induce an increase in PRA [26-27] whereas chronic hypoxia produced variable effects [28-29].

Hypoxemia alone does not stimulate the PRAPA axis. Hypercapnia may play a role but the consequences of $\mathrm{CO}_{2}$ retention on hormonal release have been examined in animal and human studies with controversial results. Experimental data demonstrated a PRA-PA axis activation during acute hypercapnia in dogs [30] and similar variation were noticed in COPD patients with acute or chronic hypercapnia $[8,9,31]$. Chabot et al studied a group of COPD patients, receiving mechanical ventilation, during moderate acute hypercapnia and concluded that changes in plasma hormones during acute hypercapnia are secondary to hemodynamic changes induced by acute respiratory failure and not to acute hypercapnia per se [32].

As a result of the stimulation of the PRA-PA axis, the activity of the angiotensin converting enzyme (ACE) is increased and high values of AnII 
may be observed; despite the inhibition of ACE activity with perindopril that seems to not change sodium excretion [33].

\section{Role of the antidiuretic hormone}

The level of plasma arginin-vasopressin $(\mathrm{ADH})$, the antidiuretic hormone, is inappropriately high for the level of plasma osmolarity in patients with hyponatremia $[8,31,33]$. If in normals the production of $\mathrm{ADH}$ is mediated by plasma osmolarity, this is not true for COPD patients where non-osmotic mechanisms should act. Although the mechanism that underlies this abnormality is not fully understood, some experimental data suggest that the increase in AnII may directly stimulate ADH [34]. Stimulation of baro-receptors in edematous patients with low circulating blood volume has also been suggested [35]. Not all patients with increased levels of ADH have hyponatraemia; in some patients $\mathrm{Na}^{+}$level remains normal until excessive water intake occurs.

\section{Role of the atrial natriuretic peptide (ANP)}

High circulating levels of atrial natriuretic factors were found in animal and human studies, which have shown that both hypoxia and hypercapnia stimulate the release of ANP [36, 37]. The highest atrial natriuretic factors levels have been observed in patients with marked sympatho-adrenergic activity and hypercapnic acidosis [36]; ANP has the effect to reduce the vascular tone and its increase during acute respiratory failure could be a compensatory mechanism induced by arterial gases worsening. In agreement with this observation was the finding that circulating ANP has been shown to correlate inversely with arterial $\mathrm{PO}_{2}$ [35]. What is not completely understood is why the increment of ANP has no influence on water and sodium renal excretion. Experimental data in COPD have shown that the PRA-PA axis is not suppressed by the increase in ANP induced by exercise [38] or by the application of lower body positive pressure [25]. It is logical to assume that, in edematous COPD patients, the effects of reduced renal blood flow, GRF and FF, induced by hypercapnia and hypoxia, are greater than those of ANP.

\section{Role of endothelin}

Recently the activation of endothelium synthesis has gained importance in the pathogenesis of vascular alteration in a group of diseases [39]. Firstly isolated in 1985 [40] as a coronary vasoconstrictor peptide produced by endothelium, endothelin-1 (ET-1) was isolated in a variety of tissues, where it acts as regulator of vasomotor tone, with a prevalent vasoconstrictor effect $[41,42]$. ET-1 causes vasoconstriction activating specific receptors on muscular smooth cells and an enhancement at the contractile response to other vasoconstrictors substances $[43,44]$ In addition ET-1 seems to be an inductor of mitogenesis of smooth muscle vascular cells.

ET-1 production seems to be involved in a number of diseases related to the vascular system. Patients with asthma and pulmonary hypertension have high levels of ET-1 in the lung $[45,46]$. Several evidences demonstrate that endothelin causes renal vasoconstriction and increases tubular sodium and water reabsorption, probably reflecting the two principal sites of production: renal blood vessels and tubules [47]. ET-1 may contribute in fact to several vascular-related diseases of the kidney, like post-ischemic renal failure [48]. Abnormal circulating ET-1 levels have been reported in stable hypoxemic COPD patients, suggesting that ET1 may contribute to pulmonary hypertension and vascular remodelling [49] in this syndrome. Both hypoxia and hypercapnia seem to contribute to blood ET-1 increment in COPD patients [50]. In a recent paper, Sofia and co-workers [51] have shown an increase in renal endothelin production in COPD patients, during acute exacerbation, in the absence of significant change in ET-1 circulating levels. Endothelin may contribute to a renal response to hypoxemia and hypercapnia in COPD.

\section{Therapeutic implications}

Table 1 summarises the most important therapeutic interventions in hypercapnic, edematous

Table 1. - Therapeutic interventions for "Cor-pulmonale" in COPD

\begin{tabular}{ll}
\hline Therapeutic intervention & Note \\
\hline - Oxygen Supplementation & $\begin{array}{l}\text { - It is the mainstay of treatment. The lowest dose }\left(\mathrm{FiO}_{2} 24 \%\right) \text {, to keep oxygen saturation > } \\
90 \% \text { should be used, in order to limit respiratory acidosis }\end{array}$ \\
- Bronchodilatators & - The highest possible broncho-dilatation should be promoted \\
- Water restriction & - Usually results in stabilization and slight increase in plasma $\mathrm{Na}^{+}$ \\
- Corticosteroids & - The use of these drugs should be limited because induces $\mathrm{Na}^{+}$retention \\
- NIV & - May reduce arterial $\mathrm{CO}_{2}$. More studies are needed \\
- Diuretics & - To be avoided. The use of diuretics may results in metabolic alkalosis and hypoventilation \\
- Digitalis & - The use of these drugs is still debated \\
\hline ACE-inibitors &
\end{tabular}


COPD patients. In view of the above findings, it is clear that the therapeutic interventions required to control edema in COPD patients should include the reversal of hypoxemia and the improvement of gas exchange and lung mechanics, by promoting maximal bronco-dilatation. Non-invasive mechanical ventilation could improve gas exchange but its effects on renal function should be better investigated. Hyponatremia, when present, should be treated with water restriction that usually results in stabilization or slight increase in plasma sodium concentration. Therapy with diuretics should be used with caution since they result in hypocloremic metabolic alkalosis, which may lead to hypoventilation with worsening of blood gas tension and, consequently, water and sodium retention [52]. The use of digitalis should be avoided unless intrinsic heart disease with low output is documented; in the presence of severe hypoxemia, the drug may expose patients to an increase risk of arrhythmias. The effect of ACE inhibitors is not completely clear and is still debated.

\section{References}

1. Campbell EJM, Short DS. The cause of edema in "cor pulmonale". Lancet 1960; I: 1184-6.

2. Reineck Hj, Stein JH. Sodium metabolism. In: Maxwell MH, Kleeman CR, Narins RG, eds. Clinical disorders of fluid and electrolyte metabolism. New York: McGraw-Hill, 1987: 39-40.

3. White RJ and Woodings DF. Impaired water handling in chronic obstructive airway disease. $B M J 1971 ; 2$ : 561-3.

4. Renzetti AD, McClement JH, Litt BD. The Veterans Administration cooperative study of pulmonary function. III. Mortality in relation to respiratory function in chronic obstructive pulmonary disease. Am J Med 1966; 41: 115-29.

5. Hodgkin JE. Prognosis in chronic obstructive pulmonary disease. Clin Chest Med 1990; 11: 550-69.

6. Lockhart A, Tzareva M, Schrijen F, et al. Etudes hemodiynamique des dècompensations respiratories aigues des bronchopneumopathies chronique. Bull Physiopathol Respir 1967; 3: 645-67.

7. Weitzenblum E, Apprill M, Oswald M, Chaouat A, Imbs JL. Pulmonary hemodynamics in patients with chronic obstructive pulmonary disease before and during an episode of peripheral edema. Chest 1994; 105: 1377-82.

8. Farber MO, Roberts LR, Weinberger MH, Robertson GL, Manfredi F. Abnormalities of sodium and $\mathrm{H}_{2} \mathrm{O}$ handling in chronic obstructive lung disease. Arch Intern Med 1982; 142: 1326-30.

9. Anand IS, Chandrashekar Y, Ferrari R, et al. Pathogenesis of congestive state in chronic obstructive pulmonary disease. Circulation 1992; 86: 12-21.

10. Fishman AP, Maxwell MH, Crowder CH, Morales P. Kidney function in cor pulmonale: particular consideration of changes in renal haemodynamics and sodium excretion during variation in level of oxygenation. Circulation 1951; 3: 703-21.

11. Sharkey RA, Mulloy EMT, Kilgallen IA, O’Neill SJ. Renal functional reserve in patients with severe chronic obstructive pulmonary disease. Thorax 1997; 52: 411415.

12. Farber MO, Bright TP, Strawbridge RA, et al. Impaired water handling in chronic obstructive lung disease. J Lab Clin Med 1975; 85: 41-9.
13. Farber MO, Kiblawi SSO, Strabridge RA, et al. Studies on plasma vasopressin and the renin-angiotensinaldosterone system in chronic obstructive pulmonary disease. J Lab Clin Med 1977; 90: 373-80.

14. Kilburn KH, Dowell AR. Renal function in respiratory failure. Effect of hypoxia, hyperoxia and hypercapnia. Arch Intern Med 1971; 127: 754-62.

15. Henriksen JH, Christensen NJ, Kok-jensen A, et al. Increased plasma noradrenaline concentration in patients with chronic obstructive pulmonary disease: relation to haemodynamics and blood gases. Scand J Clin Lab Invest 1980; 40: 419-27.

16. Badouin SV, Bott J, Ward A, et al. Short term effect of oxygen on renal haemodinamics in patients with hypoxemic chronic obstructive airways disease. Thorax 1992; 47: 550-4.

17. Sharkey RA, Mulloy EMT, O'Neill SJ. The acute effects of oxygen and carbon dioxide on renal vascular resistance in patients with acute exacerbation of COPD. Chest 1999; 115: 1588-1592.

18. Howes TQ, Deane CR, Levin GE, et al. The effects of oxygen and dopamine on renal and aortic blood flow in chronic obstructive pulmonary disease with hypoxemia and hypercapnia. Am J Resp Crit Care Med 1995; 151: 378-383.

19. Mannix ET, Dowdeswell IRG, Carlone S, et al. The effect of oxygen on sodium excretion in hypoxemic patients with chronic obstructive lung disease. Chest 1990; 97: 840-4.

20. Howes TQ, Keilty SEJ, Maskrey VL, et al. Effect of Larginine on renal blood flow in normal subjects and patients with hypoxic chronic obstructive pulmonary disease. Thorax 1996; 51: 516-519.

21. Honig A, Wedler B, Zingler C, et al. Kidney function during arterial chemoreceptor stimulation: III. Longlasting inhibition of renal tubular reabsorption due to pharmacologic stimulation of the peripheral chemoreceptors with almitrine bismesylate. Biomed Biochim Acta 1985; 44: 1659-1672.

22. Sharkey RA, Mulloy EMT, O'Neill SJ. The acute effects of hypoxemia, hyperoxemia and hypercapnia on renal blood flow in normal and renal transplant subjects. Eur Respir J 1998; 12: 653-657.

23. Raff H, Levy SA. Renin-angiotensinII-aldosterone and ACTH-cortisol control during acute hypoxemia and exercise in patients with chronic obstructive pulmonary disease. Am Rev Respir Dis 1986; 133: 396-9.

24. Richens JM, Howard P. Edema in cor pulmonale. Clin Sci 1982; 62: 255-9.

25. Carlone S, Palange P, Mannix ET. Atrial natriuretic peptide, renin and aldosterone in obstructive lung disease and heart failure. Am J Med Sci 1989; 298: 243-8.

26. Liang CS, Cavras H. Renin-angiotensin system inhibition in conscious dogs during acute hypoxemia: effects on systemic hemodynamics, regional blood flows, and tissue metabolism. J Clin Invest 1978; 62: 961-70.

27. Weismann DN, Williamson HE. Hypoxemia increases renin secretion rate in anesthetised newborn lambs. Life Sci 1981; 29: 1887-93.

28. Gould AB, Goodman SA. The effect of hypoxia on the renin-angiotensin system. Lab Invest 1970; 22: 443-7.

29. Raff H, Fagin KD. Measurements of hormone and blood gases during hypoxia in conscious cannulated rats. J App Physiol 1984; 56: 1426-30.

30. Rose CE, Kimmel DP, Godine RL, et al. Synergistic effect of acute hypoxemia and hypercapnic acidosis in conscious dogs: renal dysfunction and activation of the rennin angiotensin system. Circ Res 1983; 53: 202-13.

31. Farber MO, Weinberger MH, Robertson GL, et al. Hormonal abnormalities affecting sodium and water balance in acute respiratory failure due to chronic obstructive lung disease. Chest 1984; 85: 49-50. 
32. Chabot F, Mertes PM, Delorme N, et al. Effect of acute hypercapnia on alpha atrial natriuretic peptide, renin, angiotensin II, aldosterone, and vasopressin plasma levels in patients with COPD. Chest 1995; 107: 780-86.

33. Stewart AG, Waterhouse JC, Billings CG, et al. Effects of angiotensin converting enzyme inhibition on sodium excretion in patients with advanced chronic obstructive pulmonary disease. Thorax 1994; 49: 995-8.

34. Scrier RW, Bischet DG. Osmotic and nonosmotic control of vasopressin release and pathogenesis of impaired water excretion in adrenal, thyroid and edematous disorders. Lab Clin Med 1981; 98: 1-15.

35. Winter RJ, Davidson AC, Treacher DF, et al. Atrial natriuretic peptide concentrations in hypoxic secondary pulmonary hypertension: relation to hemodynamic and blood gas variables and response to supplemental oxygen. Thorax 1989; 44: 58-62.

36. Adnot S, Andrivet P, Chabrier PE, et al. Atrial natriuretic factor in chronic obstructive lung disease with pulmonary hypertension. J Clin Invest 1989; 181: 986-993.

37. Clozel JP, Saunier C, Hartemann D, et al. Effects of hypoxia and hypercapnia on atrial natriuretic factor and plasma renin activity in conscious dogs. Clin Sci 1989; 76: 249-254

38. Mannix ET, Manfredi F, Palange P, et al. The effect of oxygen with exercise on atrial natriuretic peptide in chronic obstructive lung disease. Chest 1992; 101: 785-789.

39. Levine ER. Endothelins. New Eng J Med 1995; 333 (6): 356-363.

40. Hickey KA, Rubanyi GM, Paul RJ et al. Characterization of a coronary vasoconstrictor produced by cultured endothelial cells. Am J Physiol 1985; 248: C550-C556.

41. Yanagisawa M, Kurihara H, Kimura S, et al. A novel potent vasoconstrictor peptide produced by vascular endothelial cells. Nature 1988; 332: 411-415.

42. Battistini B, D'Orleans-Juste P, Sirois P, et al. Endothelins: circulating plasma levels and presence in other biologic fluids. Lab Invest 1993; 68: 600-627.
43. Tabuchi Y, Nakamura M, Rakugi H, et al. Endothelin enhances adrenergic vasoconstriction in perfused rat mesenteric arteries. Biochem Biophys Res Commun 1989; 159: 1304-1308.

44. Yang Z, Richard V, von Segesser L, et al. Threshold concentrations of endothelin-1 potentiate concentrations to norepinephrine and serotonin in human arteries: a new mechanism of vasospasm? Circulation 1990; 82: 188-195.

45. Mattioli S, Soloperto M, Marini M, et al. Levels of endothelin in the bronchoalveolar lavage fluid of patients with symptomatic asthma and reversible airflow obstruction. J Allergy Clin Immunol 1991; 88: 376-384.

46. Giaid A, Michel RP, Stewart DJ, et al. Expression of endothelin-1 in lungs of patients with cryptogenic fibrosing alveolitis. Lancet 1993; 341: 1550-1554.

47. Haynes WG, Webb DJ. Endothelin as a regulator of cardiovascular function in healthy and disease. $\mathrm{J} \mathrm{Hy}$ pertens 1998; 16: 1081-1098.

48. Chan L, Chittinandana A, Shapiro Ji, Shanley PF, Schrier RW. Effect of an endothelin-receptor antagonist on ischemic acute renal failure. Am J Physiol 1994; 266: F135-F138.

49. Ferri C, Bellini C, De Angelis C, et al. Circulating endothelin-1 concentrations in patients with chronic hypoxia. J Clin Pathol 1995; 48: 519-524.

50. Fontana F, Bernardi P, Tartuferi L, et al. Mechanism of hypertension in patients with chronic obstructive pulmonary disease and acute respiratory failure. Am J Med 2000; 109: 621-627.

51. Sofia M, Maniscalco M, Celentano L, et al. Abnormalities of renal endothelin during acute exacerbation in chronic obstructive disease. Pulm Pharm \& Therap 2001; 14: 321-327.

52. Brijker F, Heijdra YF, van den Elshout FJJ, Folgering HTM. Discontinuation of furosemide decreases $\mathrm{PaCO}_{2}$ in patients with COPD. Chest 2002; 121: 377-382.

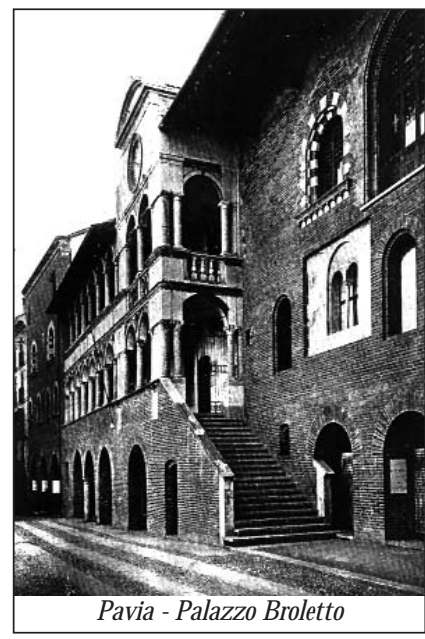

